\title{
From the Editors
}

I didn't want any flowers, I only wanted

To lie with my hands turned up and be utterly empty.

How free it is, you have no idea how free-

The peacefulness is so big it dazes you,

And it asks nothing, a name tag, a few trinkets.

It is what the dead close on, finally; I imagine them

Shutting their mouths on it, like a Communion tablet.

- Silvia Plath, Tulips

Physician-aided death, in the forms of assisted suicide or euthanasia, is already an everyday clinical occurrence. Dying patients are given doses of morphine that exceed the levels necessary to alleviate pain and end suffering. Retreating to safer ground, there is an abundance of talk about the "double effect"; yet even according to this principle, pain relief commonly and knowingly leads to permanent relief. Honest debates about physician-aided death have been hampered by a reluctance to openly acknowledge what in fact has occurred as long as medicine has been a profession. Physicians have quietly and privately helped people die faster.

Until recently The Netherlands has stood alone in its openness to discuss and practically support physician-aided death. The attitude of the Dutch cannot be explained by certain inclinations or tendencies concerning physicianassisted suicide or euthanasia per se. Even though the Dutch have a cherished history of supporting individual liberty and tolerating divergent points of view, The Netherlands is not a country with a long history of discussion about euthanasia. The Dutch Society for Voluntary Euthanasia was not founded until 1973. By contrast, in Great Britain and the United States euthanasia societies have existed since the 1930s; and euthanasia has been discussed in Germany for over a century.

Nonetheless, physician-aided death is not uncontested or universally accepted within any country, including The Netherlands: it caused a much deplored rift within the Royal Dutch Medical Society that exists to this day. The newest issues of physician-aided death have arisen in The Netherlands, in the United States where an Assisted Suicide Law that passed in Oregon was declared unconstitutional by the US District Court (now under appeal), and in the Northern Territory of Australia with the passage of the Rights of the Terminally Ill Act of 1995.

In the Special Section in this issue, Physician-Aided Death: The Escalating Debate, we explore advances of the dis- 
cussion in the world community. The particular problem of involuntary euthanasia, or what can be called mercy killing, is also addressed. Many critics of the Dutch experience focus on the category of involuntary euthanasia presented in the Remmelink report because it smacks of Nazi Germany. This objection must be met, because the Nazi backdrop is always present in euthanasia discussions, whether or not its presence is actually a valid one.

Among points for discussion and debate are whether assisted death should remain illegal, and if legalized, what sort of controls might be present, and whether there ought to be a waiting period after a request. Other more philosophical questions such as what counts as suffering, autonomy of the patient versus paternalism of the caregivers and the state, and finally, what the duties of the doctors are, have also been topics of debate.

Stories about physician-aided death are personal and problematic. They contain many of the emotional, personal risk taking, and moral predicaments of the debate about euthanasia throughout the world. As specific stories unfold, a contrasting "rightness" is also revealed. The patient finds his or her own life intolerable. Loneliness does not only stem from loss of friendship. It is an existential suffering, even though the family and friends may rally around the patient. The loneliness stems from the inevitable experience of dying, of being cut off from the activities of daily life, such as the simple acts of shopping, reading the newspaper, listening to small talk, visiting people on the corner, going to work, that is, having a "place" in the ebb and flow of life itself.

There is an impact on everyone, not the least on the patient's physician who carries out the act. It is not like putting a favorite cat or dog to sleep. This is a human being whose life is being termi- nated. Very important values and emotions are involved in any decision to acquiesce to a patient's request. Further, the risk of prosecution exists, as does the even more important risk of morally and emotionally immunizing oneself to killing and to death.

Physician-aided death in The Netherlands is part of a comprehensive program of terminal care that currently exists in the United States for only a few who choose hospice care. There are several articulated positions for promoting euthanasia in such settings, just as there are arguments against any act of participation in killing or in helping others end their lives. Dutch patients seek reassurance during the dying process that their dying will not be more than they can bear. Many citizens of other countries fear the same losses during the dying process. In exceptional cases some Dutch physicians address the need to intervene. Likewise some physicians do the same in other countries. What is the difference between them then? It lies in the Dutch ability to tolerate differences, to experiment without rushing into legislation, to educate physicians about preventing suffering, and to provide some possible immunity from prosecution.

A missing piece of the debate so far has been hearing stories from the inside-narratives of doctors and families who candidly share their experiences and thoughts on assisted death. The narratives included in this Special Section form part of a book composed of physician and family interviews conducted by us in The Netherlands in 1995. This project was made possible through support from the Gerbode Foundation which encouraged our interest in looking beyond theory to experience. No one privy to the spectrum of feelings and events discussed in those interviews could remain unmoved or unchanged. We certainly did not. For that special opportunity we wish to thank 
From the Editors

Gerbode and the Dutch physicians and to us and whose stories have left an infamily members who opened their lives delible mark.

\section{In Memorium}

We are deeply saddened by the death of James Alexander, Journals Director at Cambridge University Press, who did so much to foster the birth of this journal, encourage its first steps, and oversee its growth over the past 5 years. We extend to his family and colleagues our sincere condolences. 